\title{
THE SACCHARIMETRIC NORMAL WEIGHT AND THE SPECIFIC ROTATION OF DEXTROSE
}

\author{
By Richard F. Jackoon
}

\section{CONTENTS}

I. Introduction. ......... Page

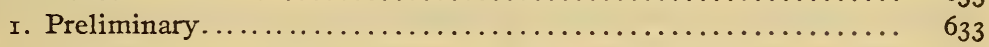

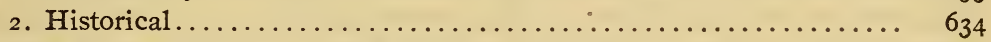

II. Preparation of pure dextrose and of dextrose solutions............ 636

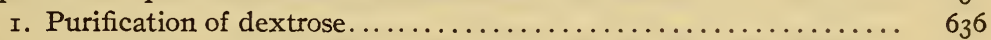

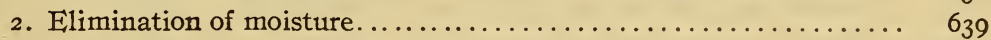

3. Preparation of solutions for polarization................. 640

4. Density of dextrose solutions ....................... $6_{4} \mathrm{I}$

III. Apparatus and temperature control ....................... $6_{42}$

r. Physical apparatus................................. 642

2. Temperature corrections $\ldots \ldots \ldots \ldots \ldots \ldots \ldots \ldots \ldots \ldots \ldots, 6_{42}$

3. Quartz control plates............................. 643

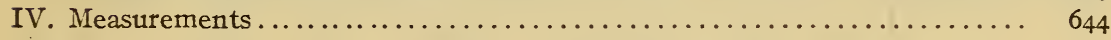

x. Determination of the normal weight of dextrose........... 644

2. The absolute rotation of the normal solution for wave length 546r A. 646

3. Variation of saccharimetric rotation with concentration of solution. 647

4. The specific rotation for wave length 546I A and its interpolation

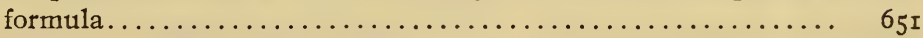

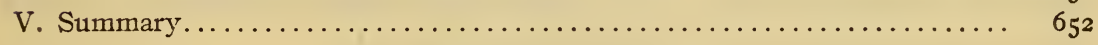

\section{INTRODUCTION}

\section{PRELIMINARY}

The polarimetric constants of the sugar group are in but few instances known with certainty. Recently the Bureau of Standards has undertaken to ascertain these values with the requisite precision and has published certain important data upon sucrose. The substance studied in the present paper, namely, dextrose, is important because of its wide distribution in nature and its commercial utility.

The purpose in view in studying dextrose was threefold. First. The purified substance was added to the list of standard samples ${ }^{1}$ of this Bureau as a standard reducing sugar, in order to assist in standardizing reducing sugar analysis. It was therefore necessary that the purification and the properties of the substance should 
receive as thorough a study as is the case with the other standard samples. Second. The normal weight required to be determined in order that the quartz-wedge saccharimeter might become arailable in analyzing the substance. Third. Its rotation of monochromatic light required further study. Bates ${ }^{2}$ has shown that the yellowgreen line of the mercury spectrum $(\lambda=546 \mathrm{rA})$ possesses many advantages over the $D$ lines of sodium light, and consequently this Bureau has advocated expressing rotation in terms of this wave length.

\section{HISTORICAL}

Previous to I8 76 a number of determinations were made of the specific rotation of dextrose before it was realized that the values obtained were functions of the concentration of the solution. In I 876 Tollens ${ }^{3}$ systematically studied the rotation and discovered the considerable variation with concentration. From his data he prepared an interpolation formula in terms of dextrose hydrate.

In 1884 he ${ }^{4}$ extended his measurements over the entire range of concentrations and recalculated his previous formula in terms of anhydrous dextrose. He expressed his first measurements by

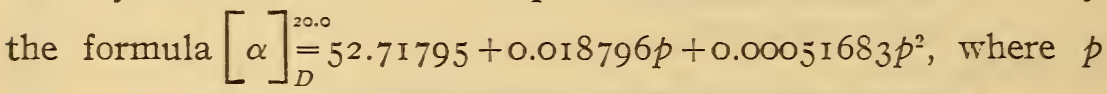
is per cent of anhydrous dextrose. The second series of measurements revealed apparently an error of about a quarter of a degree in the formula, and this amount was consequently deducted from the constant term. The resulting figure was then rounded off to 52.50 , leaving the interpolation formula

$$
[\alpha]_{D}^{20.0} 5^{2.50}+0.018796 p+0.00051683 p^{2} .
$$

Since this measurement no systematic study has been made of the rotation of dextrose.

The very divergent values which have been suggested for the normal weight are summed up by Browne. ${ }^{5}$ The entire range, including Browne's own computation, extends from $32.25 \mathrm{~g}$ to $32.82 \mathrm{~g}$, the extreme variation being about 2 per cent. The suggested value of the normal weight has in each instance been obtained by computation.

Landolt ${ }^{\beta}$ calculated from Tollens' specific rotation data the formula $p=0.948 \alpha-0.0032 \alpha^{2}$, where $p$ is per cent dextrose and $\alpha$ the rotation of the $\mathrm{D}$ lines for a $200-\mathrm{mm}$ tube. He then found 
by direct determination that the relation between the rotation on the saccharimeter with white light and the monochromatic rotation was expressed by the formula $\mathrm{I}^{\circ} \mathrm{V}=0.3448 \pm 0.0008$ circular degrees (sodium light). He then substituted the value 34.48 for a in his formula and obtained 28.88 per cent as the concentration of the solution which would rotate $100^{\circ} \mathrm{V}$ on the saccharimeter. If 28.88 is substituted for $p$ in Tollens' formula, we find $53^{\circ} \cdot 473$ for the specific rotation of the normal solution. Such a solution contains $32.65 \mathrm{~g}$ dextrose, which is thus the normal weight suggested. Inasmuch as the specific rotation varies with concentration, he proposed a different normal weight for each concentration, a preliminary assay being necessary to determine the approximate concentration.

Sidersky ${ }^{7}$ assumed for dextrose the same rotary dispersion as for sucrose (although Landolt's previous statement was to the contrary). He selected $52: 80$ as the specific rotation of the normal solution and calculated the normal weight from the inverse ratio of the specific rotations and the normal weight of sucrose $(26.00 \mathrm{~g})$. He found for the normal weight $32.82 \mathrm{~g}$.

From Tollens' equation $5^{2}: 80$ proves to be the specific rotation of a I2.I4 per cent solution of dextrose which is very far from the concentration of the normal solution on the basis of the Herzfeld-Schönrock calibration.

Tucker, ${ }^{8}$ making similar assumptions but taking the value 53 for the specific rotation of dextrose, found $32.68 \mathrm{~g}$ for the normal weight.

Browne $^{9}$ performed the calculation more carefully. $\mathrm{He}$ recalculated Tollens' formula to the more convenient form $[\alpha]_{D}^{20.0} 5^{2.50}+0.0277 c+0.00022 c^{2}$ and by successive approximations found the exact specific rotation of the normal solution. The normal weight was then calculated at first from the inverse ratio of specific rotations of sucrose and dextrose. To correct for the difference in rotation dispersion between sucrose and dextrose, he used Landolt's equation; $\mathrm{I}^{\circ} \mathrm{V}=0^{\circ} \cdot 3448$ circular degrees (sodium light) and found for the normal weight 32.248 $\mathrm{g}$ in Ioo true cubic centimeters. He advised using at all concentrations this uniform normal weight. When the concentration deviates from the normal, the correction due to the change of specific rotation is obtained from a table which he prepared. 
Browne's calculation is rigorously correct as far as the available data permit. It is, however, based upon experimental values which in themselves are far from certain. Considering the deviation between Tollens' first and second series of experiments and the advances made in polariscopic apparatus in the last 30 years, it seems probable that new data would yield more reliable values.

Landolt's data ${ }^{10}$ on the relation between $I^{\circ} \mathrm{V}$. and circular degrees of sodium light is also open to question. This value to which Landolt ascribes an uncertainty of \pm .0008 was obtained in I 866 upon a saccharimeter illuminated with white light. Since no mention is made of the use of a bichromate solution filter, it is probable that it was not used, especially since the latter did not come into general use until nearly 40 years later. The presence of the light filter would cause a considerable variation in this value.

Recently Bates and Jackson ${ }^{11}$ have made a study of the rotation of the normal sucrose solution which is the fundamental standard for the hundred-degree point of the saccharimeter. They found that the existing standard-namely, that established by Herzfeld and Schönrock-was about o.I per cent too high. Bates and Jackson by a series of careful determinations found that the conversion factor for $\lambda=5892.5 \mathrm{~A}$ was $34^{\circ}: 620$ and for $\lambda=546$ I. A $40: 690$.

\section{PREPARATION OF PURE DEXTROSE AND OF DEXTROSE SOLUTIONS}

\section{PURIFICATION OF DEXTROSE}

The material used for the preparation of pure dextrose was obtained from three sources; crude commercial glucose, Merck's "Highest Purity" dextrose, and an invert sugar solution.

The purest form of commercial glucose which could be obtained was a brownish-colored granular substance which was sold under the trade name of "Cerelose." The crude sugar contained 87.2 per cent dextrose, 3.9 per cent of nonfermentable sugar, 0.55 per cent ash, and a quantity of dextrins.

A large quantity of the glucose was shaken in a shaking machine with aqueous alcohol in order to wash the crystals. It was then poured into a centrifugal machine, drained and again washed. This preliminary treatment removed a portion of the impurities adhering to the surfaces of the crystals and assisted the later 
operations. The washed substance was then dissolved by slight warming in 40 per cent of its weight of water and 140 cubic centimeters of alcohol added for each $100 \mathrm{~g}$ of the substance. The whole mixture was warmed on a steam bath for a short time and was then filtered to remove the precipitated dextrins. The filtrate after cooling was poured into a shaking machine, seeded with a few crystals of dextrose, and agitated continuously until crystallization was complete. This usually required about 48 hours. The crystal mass was poured on the centrifugal machine, drained, and thoroughly washed with alcohol. The crystals from this first operation were fine, well-formed, and perfectly white. Upon resolution for a second crystallization there was in general but a slight trace of the original discoloration.

The second crystallization was from aqueous solution. The crystals were dissolved by warming in distilled water to form a solution of about $60^{\circ}$ Brix. The solution was filtered, cooled, and shaken in the crystallizer until crystallization was complete. Crystallization from water is particularly favorable to the formation of pure crystals. They are in every instance small and their rate of formation, which depends partly upon the speed of the reaction $\beta$ glucose $\rightarrow a$ glucose in the solution, is slow. The crystals accordingly are perfect and free from inclusions.

In the absence of special tests for possible impurities the criterion of purity which was taken was constancy of composition after treatment with varied procedure. It was found that direct recrystallization from water solution soon produced a sample which repeated recrystallizations did not alter even after four or five operations.

Attention was then turned to the mother liquors. These were boiled in vacuo in the boiling apparatus described previously ${ }^{12}$ until sufficiently supersaturated to crystallize or were united with crystals of about the same purity and the whole mixture, dissolved, concentrated, and crystallized. This process was carried out systematically in the manner usually followed in fractional crystallizations. $^{13}$ To identify the samples the numerical order of the fractions is shown in Fig. I.

Merck's "Highest Purity" dextrose was white in color and was already fairly pure. It was recrystallized from aqueous solution three times, the mother liquor being rejected after each recrystallization. The final product was designated sample M. 
For the preparation of the two invert sugar solutions from which other quantities of dextrose were prepared the purest cane sugar of commerce was utilized. One solution was inverted by invertase prepared as recommended by Hudson. ${ }^{14}$ The other was inverted by adding a small quantity of hydrochloric acid and allowing it to remain at room temperature for somewhat more than the calculated length of time sufficient to produce 99.9 per cent inversion, after which it was neutralized with sodium hydroxide. Both solutions were then boiled in vacuo until concentrated to a thick sirup. They were then mixed with a large volume of alcohol in the shaking machine and the dextrose allowed to crystallize. At the end of two or three weeks the crystals were separated in the

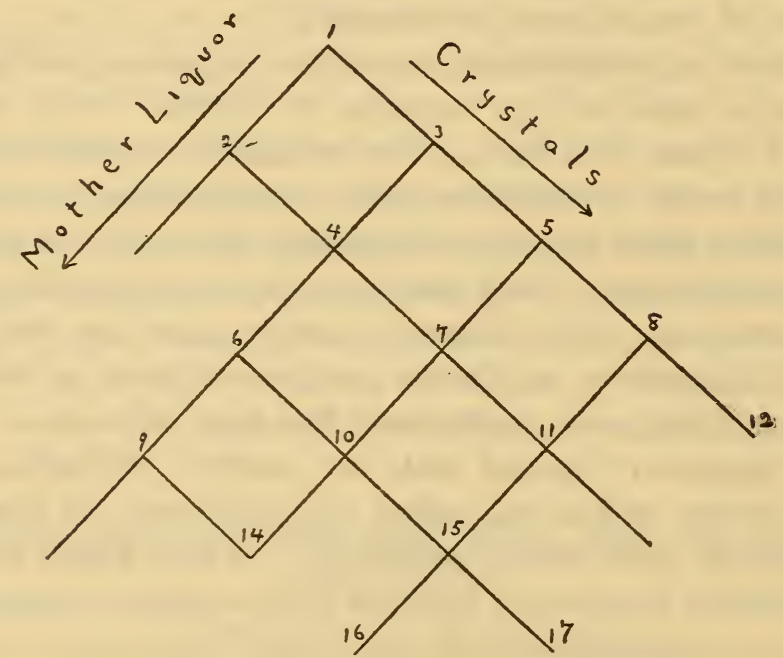

FIG. I.-Diagrammatic representation of fractional crystallization

centrifugal machine, washed, and three or four times recrystallized. The crystals from the acid inversion were designated sample $\mathrm{H}$; those from the invertase inversion sample I. Some small pure residues containing portions of both $\mathrm{H}$ and I were combined and recrystallized to form sample $J$. A considerable quantity of pure residues from various sources were combined and twice recrystallized to form sample A. A portion of this was recrystallized, the mother liquor selected and twice crystallized to form sample C.

A portion of sample $\mathrm{C}$ was dissolved in a small quantity of pure water and poured into a large quantity of nearly absolute alcohol. The crystals were almost anhydrous and were designated sample E. The accessory materials such as water and alcohol used in these preparations were purified in the usual manner. 
The probable impurities if such persisted at the completion of the purification of the sugar were of very different nature in the two sets of samples from glucose and from invert sugar. The dextrins which conceivably could contaminate the sample prepared from commercial glucose have a specific rotation of about +198 . The levulose which is the only probable impurity in the sample prepared from invert sugar has a specific rotation of about -90. The fact that the materials from the two sources had the same rotary power is strong evidence of the purity of both.

\section{ELIMINATION OF MOISTURE}

From aqueous solution dextrose separates with one molecule of crystal water. It loses this water at $60^{\circ} \mathrm{C}$, leaving the crystals in a thoroughly disintegrated condition. If it is stirred frequently the tendency to cinter together is prevented. Because of this complete disintegration the danger of inclusion of moisture within the crystals seems practically nil. The drying problem then resolves itself into the removal of surface moisture.

The first consideration was the stability of dextrose at high temperatures. Unfortunately in distinction to sucrose ${ }^{15}$ no method of detecting minute quantities of caramel exists. The most easily recognized property of caramel, namely, its power to reduce alkaline copper solutions, is entirely masked by the great reducing power of the dextrose itself. However, by leaving equal weights of sucrose and dextrose in an oven at $100^{\circ} \mathrm{C}$ overnight, it became apparent by the color change that dextrose was more resistant to a high temperature than sucrose. We therefore avoid decomposition of dextrose if we heat at any given temperature for no greater length of time than would cause a negligible caramelization of sucrose.

The sample from which the crystal water had been removed was heated electrically to $60^{\circ}$ in a weighing bottle placed in a long glass tube together with a quantity of ignited quicklime. The tube was then exhausted by a Geryk pump to about o.or mm, heating and pumping being continued for three or four hours. The bottle remained in the vacuum for two days. It was then removed and weighed. The loss in weight was about 0.02 per cent. Upon repeating the process the first dry weight was found to be constant. In fact, this was the general experience in weighing the samples for the 50 or more determinations of the rotation. 
In order to ascertain whether this constant weight represented the perfectly dry substance, three experiments were tried at higher temperatures. In each case the sample was previously dried to constant weight in the vacuum at $60^{\circ} \mathrm{C}$. One sample was then heated under the same conditions to $80^{\circ} \mathrm{C}$, the other two to $100^{\circ}$ and $125^{\circ}$, respectively. In no case was a further loss of weight discovered. If any considerable surface moisture were present, it would probably have shown some tendency to escape within a temperature interval of $65^{\circ}$.

The procedure for drying the substance in preparation for polarization then was merely to heat at $60^{\circ}$ to $70^{\circ} \mathrm{C}$ in a vacuum of $0.0 \mathrm{~mm}$ for three or four hours or until the weight became constant.

\section{PREPARATION OF SOLUTIONS FOR POLARIZATION}

In order to prepare a solution for polarization the approximate required quantity of dextrose which had been freed of its crystal water was transferred to a weighed volumetric flask and the flask and substance again weighed. The final drying was performed in a long glass tube of $8 \mathrm{~cm}$ diameter, one end of which was drawn down and connected with the vacuum pump. The other end was equipped with a ground glass joint which was large enough to permit inserting the volumetric flask. The portion of the tube containing the sample could be heated electrically to the temperature desired. The drying was repeated in every case until a constant weight was obtained.

Enough distilled water was then added to dissolve the dextrose and the solution was freed from most of the dissolved air by boiling at low temperature in a vacuum. The solution was then adjusted accurately to the graduated volume of the flask after immersion in the water of a thermostat at $20 \% 00 \mathrm{C}$ for a sufficient length of time. It was then dried by a slightly damp cloth and weighed after remaining in the balance case for a half hour.

The volumetric flasks were those used by Bates and Jackson and were described in the paper referred to. For the present work the calibration was performed repeatedly and the volumes found to be essentially identical with those found previously.

As is well known the freshly dissolved dextrose exhibits the phenomenon of mutarotation. The velocity of this reaction follows the usual law of the monomolecular reaction, its constant being fairly well established. Taking Levy's value ${ }^{16}$ of the constant at $20.7 \mathrm{C}$, namely, $\frac{\mathrm{I}}{\mathrm{t}} \log _{10} \frac{R_{\infty}-R_{0}}{R_{\infty}-R_{\mathrm{t}}}=0.00662$, we find that the 
reaction is 99.99 per cent complete in about to hours. The procedure followed was to allow the solution to stand overnight at room temperature. The flask was tightly stoppered and evaporation avoided.

\section{THE DENSITY OF DEXTROSE SOLUTIONS}

The data obtained on the concentration of the solutions were sufficient for the calculation of the density of dextrose solutions at 20 .o C. The determinations at each of the four concentrations were corrected to a uniform per cent dextrose. Each of these groups of determinations were then averaged and a series of five values obtained (see column 2 of Table I), which were sufficient for a per cent-density equation. The formula was found to be:

$$
D \frac{20^{\circ}}{4^{\circ}}=0.99840+0.003788 p+0.00001412 p^{2}
$$

where $p$ is per cent dextrose by weight in vacuo. The density as computed by this formula may be considered valid to three or four units in the fifth decimal place for values of $p$ between 5 and 30 . In column 3 of Table $\mathrm{I}$ are given the densities as calculated by the formula. Their agreement with the experimental data is shown by the residuals in column 4 . In Table 2 the densities are given at I per cent intervals between 4 and 30 per cent.

The only previous determination at $20.0 \mathrm{C}$ is a series made by Tollens ${ }^{17}$ incidentally to his measurements of the rotation. For the sake of comparison we may cite his values at 7.60, I0.14, and I 7.60 per cent, for which he found densities I.0282, I.0383, and r.0694, respectively. The corresponding densities found in the present investigation are $\mathrm{I} .0280 \mathrm{I}, \mathrm{x} .03826$, and I.06945.

TABLE 1

Data on Density of Dextrose Solutions and Comparison with Interpolation Formula

\begin{tabular}{|c|c|c|c|}
\hline $\begin{array}{c}\text { Concen- } \\
\text { tration by } \\
\text { weight } \\
\text { in vacuo }\end{array}$ & $\begin{array}{c}\text { Density } 20^{\circ} / 4^{\circ} \\
\text { observed }\end{array}$ & $\begin{array}{c}\text { Density } 20^{\circ} / 4^{\circ} \\
\text { calculated } \\
\text { from formula }\end{array}$ & $\begin{array}{c}\text { Residuals, } \\
\text { col. 3-col.2 }\end{array}$ \\
\cline { 2 - 4 } 1 & 2 & 3 & 4 \\
\hline Per cent & & & \\
6.5 & 1.02361 & 1.02362 & +0.00001 \\
12.5 & 1.04799 & 1.04796 & -.00003 \\
18.5 & 1.07329 & 1.07331 & +.00002 \\
23.5 & 1.09524 & 1.09522 & -.00002 \\
28.9 & 1.11963 & 1.11966 & +.00003 \\
\hline
\end{tabular}

${ }^{17}$ Landolt and Börnstein, Tabellen, p. 79; 1912. 
TABLE 2

Density of Dextrose Solutions Calculated by Formula:

$$
\mathrm{D} \frac{20^{\circ}}{4^{\circ}}=0.99840+0.003788 \mathrm{p}+0.00001412 \mathrm{p}^{2}
$$

\begin{tabular}{|c|c|c|c|c|c|}
\hline $\begin{array}{c}\text { Concen- } \\
\text { tration by } \\
\text { weight } \\
\text { in vacuo }\end{array}$ & Density $\frac{20^{\circ}}{4^{\circ}}$ & $\begin{array}{c}\text { Concen- } \\
\text { tration by } \\
\text { weight } \\
\text { in vacuo }\end{array}$ & Density $\frac{20^{\circ}}{4^{\circ}}$ & $\begin{array}{c}\text { Concen- } \\
\text { tration by } \\
\text { weight } \\
\text { in vacuo }\end{array}$ & Density $\frac{20^{\circ}}{4^{\circ}}$ \\
\cline { 1 - 3 } Per cent & & Per cent & & Per cent & \\
4 & 1.01378 & 13 & 1.05003 & 22 & 1.08857 \\
5 & 1.01769 & 14 & 1.05420 & 23 & 1.09239 \\
6 & 1.02164 & 15 & 1.05840 & 24 & 1.09744 \\
7 & 1.02561 & 16 & 1.06262 & 25 & 1.10192 \\
8 & 1.02961 & 17 & 1.06588 & 26 & $1.106+3$ \\
9 & 1.03364 & 18 & 1.07116 & 27 & 1.11037 \\
10 & 1.03769 & 19 & 1.07547 & 28 & 1.11553 \\
11 & 1.04178 & 20 & 1.07981 & 29 & 1.12013 \\
12 & 1.04589 & 21 & 1.08417 & 30 & 1.12475 \\
\hline
\end{tabular}

\section{APPARATUS AND TEMPERATURE CONTROL}

\section{PHYSICAL APPARATUS}

The polariscopic apparatus which was used for the observations was fully described in the paper by Bates and Jackson. ${ }^{18}$ The discussion on pages 97 to IOS is directly applicable to the present paper. The method of taking observations was also similar to that in the earlier work.

\section{TEMPERATURE CORRECTIONS}

The temperature corrections for the optical apparatus were described by Bates and Jackson ${ }^{10}$ and are directly applicable to the present measurements. The temperature coefficient of the dextrose solutions, however, required especial attention. The temperature coefficient of the specific rotation of dextrose solutions has been previously studied over a wide range of temperatures and has been found to be zero. Since in the present work the variations of temperature were very small, it is permissible to accept this result without question. The actual change of rotation with change of temperature, then, would be due entirely to the change in volume of the solution. The expansion of the normal solution was measured in the vicinity of $20^{\circ} \mathrm{C}$ and found to be 0.00029 . This figure was then also the temperature correction factor for the rotation. 
In addition to this the actual temperature coefficient of rotation was measured for a number of solutions. The data obtained were the very small differences between large numbers and consequently a great many were required to offset the errors of observation. The mean of 37 such determinations gave for the coefficient 0.00028 . The mean value 0.000285 was used in the computations at the normal concentrations. For the lower rotations the expansion coefficient was taken to be proportional to the concentration of dextrose between pure water which has a coefficient of 0.0002 I and the normal dextrose solution 0.000285 . The expansion coefficient is probably not strictly linear with concentration but for the present purpose where the entire correction is small the deviations from the linear relation are negligible. The correction to be applied is then proportional to the rotation and to the expansion coefficient.

\section{QUARTZ CONTROL PLATES}

There was available for the present investigation a set of seven quartz plates, all of excellent quality, optically homogeneous, and nearly plane parallel, which constitute part of a series of primary standards of this Bureau. Their properties, including their rotations in terms of wave lengths $5892.5 \mathrm{~A}$ and $546 \mathrm{I} \mathrm{A}$, have been been studied at this Bureau and at the Physikalisch-Technische Reichsanstalt. The results of the thorough study which these plates have received will be stated in a future publication of this Bureau. Their sugar values were found by dividing their monochromatic rotations by the appropriate conversion factors. For the present work the factors determined by Bates and Jackson, namely, $34^{\circ} \cdot 620$ for $\lambda=5892.5 \mathrm{~A}$ and $40: 690$ for $\lambda=546 \mathrm{I} \mathrm{A}$, have been used. Until the final value of the conversion factor is generally agreed upon it is considered of more importance that the proposed normal weight of dextrose shall correspond exactly with $26.000 \mathrm{~g}$ of sucrose than with the Herzfeld-Schönrock scale, which is now known to be slightly in error.

A further assumption made in regard to the saccharimetric scale is that the scale readings are rigorously proportional to the rotation of quartz. For example, if a quartz plate rotates $17^{\circ} \cdot 3$ IO for $\lambda=5892.5 \mathrm{~A}$, its sugar value is exactly $50: 00$. The same conversion factor is thus applicable to all parts of the saccharimeter scale. This is equivalent to the statement that the saccharimeter scale is proportional to the thickness of the compensating quartz. 


\section{MEASUREMENTS}

\section{DETERMINATION OF THE NORMAL WEIGHT OF DEXTROSE}

Twelve independent measurements were made to determine the weight of dextrose which dissolved in Ioo true cubic centimeters causes a rotation of $100^{\circ} \mathrm{S}$ on the sugar scale as determined by Bates and Jackson. The data acquired during the measurements are recorded in Table 3 . The values of the normal weight obtained are given in column 7 and were calculated in the following way: The concentration of sugar in each experiment was found by dividing the weight of substance (column 3) by the volume of solution (column 5). The concentration was then divided by the rotation of the solution to give a value of the normal weight which would be the true value, provided the specific rotation were precisely constant over the small range of concentrations measured. This is not exactly true, so that a small correction was applied to bring the normal weight to the value which would have been obtained if the solution observed were at the normal concentration. The specific rotation, as will be shown later, is changing at this concentration $0.02 \mathrm{I}$ per cent for each sugar degree change in concentration. The calculated value of the normal weight is then 0.02 I per cent, or $6.9 \mathrm{mg}$ too low for each sugar degree above $100^{\circ}$ $\mathrm{S}$ which the observed solution reads. This correction has been applied and the corrected value recorded in column 7 . As appears from the table, the true normal weight of dextrose, or that weight of dextrose which produces on the saccharimeter the same rotation as $26.000 \mathrm{~g}$ of sucrose, is $32.23 \mathrm{I} \mathrm{g}$ weighed in air with brass weights. ${ }^{20}$

The value $32.23 \mathrm{I}$ is dependent on the assumption that the hundred-degree point of the saccharimeter is defined according to the conversion factor $34: 620$ for $\lambda=5892.5 \mathrm{~A}$ and $40: 690$ for $\lambda=546 \mathrm{I} \mathrm{A}$. If some other standard is used the normal weight is determined by the following relation:

or

$$
\text { Normal weight }=\frac{\text { conversion factor }}{34.620} \times 32.23 \mathrm{I}(\lambda=5892.5 \mathrm{~A})
$$

$$
\text { normal weight }=\frac{\text { conversion factor }}{40.690} \times 32.23 \mathrm{I}(\lambda=546 \mathrm{IA}) .
$$

${ }^{20}$ To specify more rigorously, this is the weight in air of density $0.00 \mathrm{Ig}$, the mean value during the present experiments. 
This formula is strictly applicable for small differences in the conversion factor. Here, again, if the change in weight is enough to cause a measurable change in the specific rotation, a correction of $6.9 \mathrm{mg}$ must be applied for each degree sugar or each $0: 346$ or $0: 407$, by which the factor chosen exceeds $34: 620$, or $40: 690$ for the respective wave lengths. Thus, if the saccharimeter is standardized, as at present, by the Herzfeld-Schönrock factor $34^{\circ} \cdot 657$, the normal weight of dextrose becomes $32.264 \mathrm{~g}$. In order to avoid confusion it must be noted that the Herzfeld-Schönrock factor is the one in general use at the date of this publication. If the saccharimeter is controlled by quartz plates certified by this Bureau or by the Physikalish-Technische Reichsanstalt, the Herzfeld-Schönrock data have been used and until further notice will continue to be used in determining the sugar value. Consequently, the weight 32.264 must be taken to rotate $100^{\circ} \mathrm{S}$. But if the saccharimeter has been standardized by careful observations of $26.000 \mathrm{~g}$ of pure sucrose in roo cc, or if, as is to be hoped, the conversion factor is modified to $34^{\circ}: 620$ and $40: 690$, the normal weight of dextrose becomes $32.23 \mathrm{I}$.

\section{TABLE 3}

Data on the Concentration and Rotation of the Normal Solution

\begin{tabular}{|c|c|c|c|c|c|c|c|c|}
\hline Expt. No. & $\begin{array}{l}\text { Designation of } \\
\text { sample }\end{array}$ & $\begin{array}{c}\text { Weight } \\
\text { of } \\
\text { dextrose } \\
\text { (air, } \\
\text { brass } \\
\text { weights) }\end{array}$ & $\begin{array}{c}\text { Weight } \\
\text { of } \\
\text { solution } \\
\text { (air, } \\
\text { brass } \\
\text { weights) }\end{array}$ & $\begin{array}{c}\text { Volume } \\
\text { of } \\
\text { solution }\end{array}$ & $\begin{array}{l}\text { Average } \\
\text { observed } \\
\text { rotation } \\
\text { for two } \\
\text { saccha- } \\
\text { rimeters }\end{array}$ & $\begin{array}{l}\text { Normal } \\
\text { weight }\end{array}$ & $\begin{array}{c}\text { Rotation } \\
\text { observed } \\
\lambda=5461 \mathrm{~A}\end{array}$ & $\begin{array}{l}\text { Rotation } \\
\text { of normal } \\
\text { solution } \\
\lambda=5461 \mathbf{A}\end{array}$ \\
\hline \multirow[t]{2}{*}{1} & 2 & 3 & 4 & 5 & 6 & 7 & 8 & 9 \\
\hline & Fraction $5 .$. & $\begin{array}{c}\mathrm{g} \\
32.5255\end{array}$ & $\begin{array}{c}\mathrm{g} \\
112.096\end{array}$ & $\begin{array}{c}c c \\
100.166\end{array}$ & $\begin{array}{c}\text { sugar deg. } \\
100.753\end{array}$ & $\begin{array}{c}\mathrm{g} \\
32.234\end{array}$ & $\begin{array}{l}\text { deg. } \\
. . .\end{array}$ & deg. \\
\hline $2 \ldots$ & $\ldots .$. do..... & 32.3283 & 112.039 & 100.183 & 100.114 & 32.233 & ....... & (n...... \\
\hline $3 \ldots$ & Fraction $8 \ldots$ & 31.8702 & ........... & 100.185 & …… & ......... & 40.362 & 40.904 \\
\hline $4 \ldots .$. & .....do...... & 32.4030 & 111.889 & 100.005 & 100.563 & 32.222 & .......... & ....... \\
\hline $5 \ldots$ & Fraction 15. & 32.4778 & .112 .103 & 100.181 & 100.604 & 32.228 & .......... & ...... \\
\hline $6 .$. & Fraction $11 .$. & 41.7989 & .......... & 130.063 & 99.693 & 32.233 & 40.780 & 40.901 \\
\hline $7 \ldots$ & Sample C... & 41.9946 & 145.439 & 130.032 & 100.180 & 32.239 & 40.978 & 40.895 \\
\hline $8 \ldots \ldots$ & Fraction $15 \ldots$ & 42.9000 & ............. & 129.997 & 102.453 & 32.228 & .......... & (....... \\
\hline $20 \ldots \ldots$. & Sample C.... & 32.1525 & 111.792 & 99.993 & 99.748 & 32.232 & 40.792 & 40.894 \\
\hline $21 \ldots$ & .... do ........ & 30.4514 & 105.286 & 94.121 & 100.377 & 32.235 & 41.051 & 40.893 \\
\hline $24 \ldots$ & Fraction $8 . .$. & 30.1672 & 105.180 & 94.121 & 99.436 & 32.230 & 40.659 & 40.892 \\
\hline $28 \ldots .$. & Sample H... & 32.2959 & 112.033 & 100.181 & 100.026 & 32.229 & 40.921 & 40.912 \\
\hline $54 \ldots \ldots \ldots$. & Sample I...... & 32.2670 & 112.027 & 100.187 & 99.914 & 32.234 & 40.857 & 40.888 \\
\hline & & & & & & 32.231 & & 40.897 \\
\hline
\end{tabular}




\section{THE ABSOLUTE ROTATION OF THE NORMAL SOLUTION FOR WAVE} LENGTH 5461 A

The observations on each solution included, when possible, its rotation in circular degrees for the yellow-green mercury line $\lambda=546 \mathrm{I} A$. These readings were made on the same day as the saccharimeter readings, either preceding or following them. The accepted rotation was the mean of the readings of two observers upon two or three polariscope tubes containing portions of the same solution. The practice was to make about six settings of the instrument for each tube and an equal number for the zero point in alternation. Frequent readings of the thermometers in the air bath or in the polariscope tubes were also taken. At frequent intervals one of the standard quartz plates was read in order to ascertain whether the rotations were consistent with previous measurements. Bates and Jackson applied a correction of -0.004 to the reading of the normal sucrose solution in order that the value should be the mean of the various optical systems used to purify the light source. This correction has also been applied in the present instance to the normal solution and to the more dilute solutions proportionate'y to the magnitude of the rotation.

The observed rotations are recorded in column 8 of Table 3 . These values were transformed to give the rotations of the normal solution by the simple relation:

\section{$\frac{\text { Normal weight }}{\text { Weight taken in IOo cc }} \times$ rotation observed.}

This gave a value of the normal rotation which depended upon the assumption that the specific rotation was constant over the range of rotations observed. As this was not strictly true, a small correction was applied. It will be shown later (p. $65 \mathrm{I}$ ) that the specific rotation varies $0: 0136$, or 0.0214 per cent for each sugar-degree deviation from the normal concentration. Accordingly, a correction of -0.00875 was applied for each sugar degree above $100: 00 \mathrm{~S}$ which the solution rotated. This has been applied in order to obtain the corrected values in column 9. The conclusion is that light of wave length $546 \mathrm{I} \mathrm{A}$ is rotated $40: 897$ by the normal solution at $20 \% 00$. It is evident from a consideration of the data now available that the rotary dispersion curves of quartz and of dextrose deviate considerably from each other. The normal plate which gives on the saccharimeter a rotation 
identical with the normal dextrose solution. rotates wave length 5461 A 40:690, while the dextrose solution rotates it $40: 897$.

There is thus a difference of $0: 2$ in the rotation of this wave length when the quartz wedges are set for a photometric match. Although this color is only 4 per cent transmitted by the 6 per cent and I $5 \mathrm{~mm}$ bichromate cell, the transmission curve ${ }^{21}$ of the latter rises abruptly at this point with increasing wave length. We must, then, conclude that the photometric field is considerably heterochromatic and the eye is obliged to match an intensity of one color by a supposedly equal intensity of a slightly different color. For sucrose 22 the normal solution rotates wave length 546I A 40:763, which, by comparison with quartz $40: 690$, indicates a much closer agreement of rotary dispersion curves. We should, therefore, expect a lower degree of reproducibility in reading dextrose than sucrose solutions. This proves in some measure to be the case, but in the process of taking the mean of a sufficient number of readings, the differences apparently disappear.

Furthermore, as the observer's experience increases there proves to be a corresponding improvement in reproducibility. Thus, in experiment No. I the readings were scattered over a range of $0: 26 \mathrm{~S}$; in No. 2 the greatest difference was 0 : I 2 S. In the whole series, exclusive of experiments $I$ and 2, the two observers, reading the same solution upon the same instrument, agreed within $0: 03 \mathrm{~S}$.

The experiment was tried of doubling the concentration of bichromate solution, but it did not appear to increase the reproducibility of setting. It was then decided to postpone any further work on a suitable light filter until the rotary dispersion curve of dextrose was known with suitable precision.

\section{VARIATION OF SACCEARIMETRIC ROTATION WITH CONCENTRATION OF SOLUTION}

In addition to the rotation of dextrose at the normal concentration a complete series of measurements was made at each of four other concentrations, namely, $4 / 5,3 / 5,2 / 5$, and $1 / 5$ normality. At each of these concentrations the measurements were conducted in exactly the same manner as for the normal concentration, the rotations being compared upon two saccharimeters with the readings of the standard quartz plates.

The experimental work at these concentrations is recorded in Tables $4,5,6$, and 7 . An experiment at $80^{\circ} \mathrm{S}$. may be taken as 
an example. About $4 / 5$ the normal weight was weighed in the volumetric flask, dried, weighed, and dissolved in the usual manner, the data being given in columns 3,4 , and 5. Its rotation was measured with all the precautions and with as many settings of the instruments as in the case of the normal solution. The mean of these readings is given in column 6 . The rotation of the $4 / 5$ normal solution was computed by the relation

$$
\frac{\text { Observed rotation }}{\text { Concentration }} \times 4 / 5 \times 32.231
$$

The result of this computation would be true if the specific rotation were constant over the range of the observed rotations. This is not strictly so, and accordingly a small correction obtained in the manner indicated for the normal solution has been applied. The corrected values are given in column 7. The mean of column 7 in Table 4-namely, 79.639-shows the result of a very considerable deviation of specific rotation with change of concentration. If the specific rotation were constant, the $4 / 5$ normal solution would have read 80.000 . The measurements illustrate the importance of applying a correction for concentration when the solution deviates from the normal. Although the deviation of specific rotation is progressive as the dilution increases, the correction passes through a maximum. If expressed in percentage of the measured rotation, the correction is linear.

TABLE 4

Data on the Concentration and Rotation of the $4 / 5$ Normal Solution

\begin{tabular}{|c|c|c|c|c|c|c|c|c|}
\hline Expt. No. & $\begin{array}{l}\text { Designation of } \\
\text { sample }\end{array}$ & $\begin{array}{l}\text { Weight } \\
\text { of } \\
\text { dextrose } \\
\text { (air, } \\
\text { brass } \\
\text { weights) }\end{array}$ & $\begin{array}{l}\text { Weight } \\
\text { of } \\
\text { solution } \\
\text { (air, } \\
\text { brass } \\
\text { weights) }\end{array}$ & $\begin{array}{c}\text { Volume } \\
\text { of } \\
\text { solution }\end{array}$ & $\begin{array}{l}\text { Average } \\
\text { observed } \\
\text { rotation } \\
\text { on two } \\
\text { saccha- } \\
\text { rimeters }\end{array}$ & $\begin{array}{c}\text { Rotation } \\
\text { of } 4 / 5 \\
\text { normal } \\
\text { solution }\end{array}$ & $\begin{array}{c}\text { Rotation } \\
\text { observed } \\
\lambda=5461 \mathrm{~A}\end{array}$ & $\begin{array}{c}\text { Rotation } \\
\text { of } 4 / 5 \\
\text { normal } \\
\text { solution } \\
\lambda=5461 \mathrm{~A}\end{array}$ \\
\hline \multirow[t]{2}{*}{1} & 2 & 3 & 4 & 5 & 6 & 7 & 8 & 9 \\
\hline & \multirow{3}{*}{$\begin{array}{c}\text { Sample A.... } \\
\ldots \ldots \text {. do......... }\end{array}$} & g & $g$ & $\mathrm{cc}$ & sugar deg. & sugardeg. & deg. & deg. \\
\hline $9 .$. & & 33.5756 & 142.314 & 130.018 & 79.755 & 79.633 & ......... & n........ \\
\hline $10 \ldots$ & & 25.7430 & 109.607 & 100.183 & 79.368 & 79.647 & 32.459 & 32.572 \\
\hline $22 \ldots$. & \multirow{6}{*}{$\begin{array}{l}\text { Sample I..... } \\
\text { Sample C.... } \\
\text { Sample M ... } \\
\text { Sample J..... } \\
\text { Fraction } 16 . . .\end{array}$} & 33.4408 & 142.259 & 130.004 & 79.445 & 79.639 & 32.495 & 32.575 \\
\hline $23 . . . .$. & & 25.6511 & 109.622 & 100.223 & 79.023 & 79.623 & 32.321 & 32.567 \\
\hline $30 \ldots .$. & & 25.8337 & ........... & 100.181 & 79.646 & 79.639 & 32.5825 & 32.579 \\
\hline $40 \ldots \ldots$ & & 25. 5835 & 109.548 & 100.181 & 78.870 & 79.647 & 32.270 & 32.588 \\
\hline $52 \ldots \ldots \ldots \ldots$ & & 25.6668 & ............ & 100.184 & 79.123 & 79.642 & 32.354 & 32.566 \\
\hline & & & & & & 79.639 & & 32.5745 \\
\hline
\end{tabular}


TABLE 5

Data on the Concentration and Rotation of the $3 / 5$ Normal Solution

\begin{tabular}{|c|c|c|c|c|c|c|c|c|}
\hline Expt. No. & $\begin{array}{l}\text { Designation of } \\
\text { sample }\end{array}$ & $\begin{array}{c}\text { Weight } \\
\text { of } \\
\text { dextrose } \\
\text { (air, } \\
\text { brass } \\
\text { weights) }\end{array}$ & $\begin{array}{l}\text { Weight } \\
\text { of } \\
\text { solution } \\
\text { (air, } \\
\text { brass } \\
\text { weights) }\end{array}$ & $\begin{array}{c}\text { Volume } \\
\text { of } \\
\text { solution }\end{array}$ & $\begin{array}{c}\text { Average } \\
\text { observed } \\
\text { rotation } \\
\text { on two } \\
\text { saccha- } \\
\text { rimeters }\end{array}$ & $\begin{array}{c}\text { Rotation } \\
\text { of } 3 / 5 \\
\text { normal } \\
\text { solution }\end{array}$ & $\begin{array}{l}\text { Rotation } \\
\text { observed } \\
\lambda=5461 \text { A }\end{array}$ & $\begin{array}{c}\text { Rotation } \\
\text { of } 3 / 5 \\
\text { normal } \\
\text { solution } \\
\lambda=5461 \mathrm{~A}\end{array}$ \\
\hline \multirow[t]{2}{*}{1} & 2 & 3 & 4 & 5 & 6 & 7 & 8 & 9 \\
\hline & Fraction $8 \ldots$ & $\begin{array}{c}g \\
19.4089\end{array}$ & $\begin{array}{c}g \\
107.245\end{array}$ & $\begin{array}{c}c c \\
100.181\end{array}$ & $\begin{array}{c}\text { sugar deg. } \\
59.597\end{array}$ & $\begin{array}{c}\text { sugar deg. } \\
59.488\end{array}$ & $\begin{array}{l}\text { deg: } \\
24.371\end{array}$ & $\begin{array}{l}\text { deg. } \\
24.325\end{array}$ \\
\hline $14 \ldots$. & ....do.......... & 19. 5009 & 107.321 & 100.223 & 59.910 & 59.539 & 24.486 & 24.334 \\
\hline $17 \ldots$ & Sample C.... & 18.7139 & $\ldots \ldots \ldots$ & 94.121 & 61.173 & 59.477 & 25.013 & 24.320 \\
\hline $18 .$. & .....do........ & 20.0355 & 107.509 & 100.223 & 61.524 & 59.490 & 25.160 & 24.328 \\
\hline $34 .$. & Fraction $17 \ldots$ & 19.6780 & 107.344 & 100.181 & 60.437 & 59.490 & 24.710 & 24.323 \\
\hline $38 \ldots$ & Sample I..... & 18.9178 & 101.014 & 94.121 & 61.846 & 59.475 & 25.303 & 24.333 \\
\hline $55 \ldots \ldots \ldots$ & Fraction $15 \ldots$ & 17.6856 & …...... & 90.801 & 59.912 & 59.480 & 24.512 & 24.335 \\
\hline & & & & & & 59.491 & & 24.328 \\
\hline
\end{tabular}

TABLE 6

Data on the Concentration and Rotation of the 2/5 Normal Solution

\begin{tabular}{|c|c|c|c|c|c|c|c|c|}
\hline Expt. No. & $\begin{array}{l}\text { Designation of } \\
\text { sample }\end{array}$ & $\begin{array}{l}\text { Weight } \\
\text { of } \\
\text { dextrose } \\
\text { (air, } \\
\text { brass } \\
\text { weights) }\end{array}$ & $\begin{array}{l}\text { Weight } \\
\text { of } \\
\text { solution } \\
\text { (air, } \\
\text { brass } \\
\text { weights) }\end{array}$ & $\begin{array}{l}\text { Volume } \\
\text { of } \\
\text { solution }\end{array}$ & $\begin{array}{c}\text { Average } \\
\text { observed } \\
\text { rotation } \\
\text { on two } \\
\text { saccha- } \\
\text { rimeters }\end{array}$ & $\begin{array}{c}\text { Rotation } \\
\text { of } 2 / 5 \\
\text { normal } \\
\text { solution }\end{array}$ & $\begin{array}{c}\text { Rotation } \\
\text { observed } \\
\lambda=5461 \mathrm{~A}\end{array}$ & $\begin{array}{c}\text { Rotation } \\
\text { of } 2 / 5 \\
\text { normal } \\
\text { solution } \\
\lambda=5461 \mathrm{~A}\end{array}$ \\
\hline \multirow[t]{2}{*}{1} & 2 & 3 & 4 & 5 & 6 & 7 & 8 & 9 \\
\hline & Sample A.... & $\begin{array}{c}g \\
12.8269\end{array}$ & $\begin{array}{c}g \\
104.818\end{array}$ & $\begin{array}{c}c c \\
100.223\end{array}$ & $\begin{array}{c}\text { sugar deg. } \\
39.200\end{array}$ & \begin{tabular}{|} 
sugar deg. \\
39.490
\end{tabular} & $\begin{array}{l}\text { deg. } \\
16.032\end{array}$ & $\begin{array}{l}\text { deg. } \\
16.151\end{array}$ \\
\hline 15. & Fraction $8 . .$. & 17.2069 & 136.190 & 130.016 & 40.558 & 39.501 & 16.577 & 16.145 \\
\hline 16. & Sample A.... & 13.2657 & 104.763 & 100.000 & 40.623 & 39.470 & 16.603 & 15.132 \\
\hline $31 .$. & Sample M.... & 12. 1053 & 98.453 & 94.121 & 39.372 & 39.468 & 16.094 & 16.133 \\
\hline 43. & .....do.......... & 12.1226 & 98.470 & 94.121 & 39.456 & 39.495 & 16.140 & 16.156 \\
\hline 46. & ..... do.... & 12.9342 & 104.817 & 100.181 & 39.529 & 39.473 & 16.161 & 16.138 \\
\hline $50 \ldots \ldots \ldots$ & Sample E.... & 12. 2315 & ........... & 94.121 & 39.807 & & 16.268 & 16.138 \\
\hline Av.... & & & & & & 39.484 & & 16.142 \\
\hline
\end{tabular}

F. P. Phelps very kindly performed a least square adjustment of the straight line representing the percentage deviation of rotation from strict proportionality. In this adjustment the normal weight was taken as the fixed value $32.23 \mathrm{I} \mathrm{g}$ and the remaining four series weighted in proportion to the magnitude of the rotation.

The corrections to be applied are given for $5^{\circ} \mathrm{S}$ intervals in Table 8. These quantities are valid for all readings in a $200 \mathrm{~mm}$ tube. If the solution is read in a $400 \mathrm{~mm}$ tube, the reading is 
divided by 2 to find the correction. The latter is then multiplied by 2 and applied to the original reading.

\section{TABLE 7}

Data on the Concentration and Rotation of the 1/5 Normal Solution

\begin{tabular}{|c|c|c|c|c|c|c|c|c|}
\hline Espt. No. & $\begin{array}{l}\text { Designation of } \\
\text { sample }\end{array}$ & $\begin{array}{l}\text { Weight } \\
\text { of } \\
\text { dertrose } \\
\text { (air, } \\
\text { brass } \\
\text { weights) }\end{array}$ & $\begin{array}{l}\text { Weight } \\
\text { of } \\
\text { solution } \\
\text { (air, } \\
\text { brass } \\
\text { meights) }\end{array}$ & $\begin{array}{l}\text { Volume } \\
\text { of } \\
\text { solution }\end{array}$ & $\begin{array}{l}\text { Average } \\
\text { observed } \\
\text { rotation } \\
\text { on two } \\
\text { saccha- } \\
\text { rimeters }\end{array}$ & $\begin{array}{l}\text { Rotation } \\
\text { of } 1 / 5 \\
\text { normal } \\
\text { solution }\end{array}$ & $\begin{array}{l}\text { Rotation } \\
\text { observed } \\
\lambda=5461 \mathrm{~A}\end{array}$ & $\begin{array}{l}\text { Rotation } \\
\text { of } 1 / 5 \\
\text { normal } \\
\text { solution } \\
\lambda=5461 \mathrm{~A}\end{array}$ \\
\hline \multirow[t]{2}{*}{1} & 2 & 3 & 4 & 5 & 6 & 7 & 8 & 9 \\
\hline & Sample C..... & $\begin{array}{l}g \\
6.8326\end{array}$ & $\begin{array}{c}8 \\
102.503\end{array}$ & $\begin{array}{c}c c \\
100.181\end{array}$ & $\begin{array}{c}\text { sugar deg. } \\
20.813\end{array}$ & $\begin{array}{c}\text { sugar deg. } \\
19.666\end{array}$ & $\begin{array}{l}\text { deg. } \\
8.506\end{array}$ & $\begin{array}{l}\text { deg. } \\
8.038\end{array}$ \\
\hline $26 \ldots$ & Fraction $8 . . .$. & 6.7750 & 102.523 & 100.223 & 20.631 & 19.670 & 8.442 & 8.049 \\
\hline $33 \ldots$ & Fraction $17 \ldots$ & 6.8384 & 102.550 & 100.223 & 20.823 & 19.658 & 8.518 & 8.045 \\
\hline $37 \ldots .$. & Sample I...... & 6.6511 & 102.440 & 100.181 & 20.235 & 19.644 & 8.292 & 8.050 \\
\hline $41 \ldots$. & .... do.......... & 6.9544 & 102.551 & 100.181 & 21.144 & 19.628 & 8.658 & 8.038 \\
\hline $49 \ldots$. & Sample D.... & 8.6443 & 132.936 & 130.000 & 20.230 & 19.609 & 8.287 & 8.032 \\
\hline $53 \ldots .$. & Sample E..... & 6.0056 & 92.251 & 90.214 & 20.291 & 19.645 & 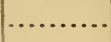 & 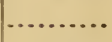 \\
\hline Av. & & & & & & 19.647 & & 8.042 \\
\hline
\end{tabular}

As has been stated, Browne computed a similar table by using Tollens' data on the specific rotation. Browne's table gives very similar values at the higher values of the rotation, but it deviates from the present direct determination at the lower rotations. For example, the corrections at $80^{\circ} \mathrm{S}, 40^{\circ} \mathrm{S}$, and $20^{\circ} \mathrm{S}$ are according to Browne's computation $+.035,+0.48$, and +0.30 , respectively, The corresponding corrections from the present work are +0.35 , +0.53 , and +0.35 . The deviation seems to cast some doubt upon the second order correction of the specific rotation formula of Tollens from which Browne's data were computed.

\section{TABLE 8}

Corrections to be Applied to Saccharimetric Readings of Dertrose Solutions

\begin{tabular}{|c|c|c|c|c|c|}
\hline $\begin{array}{c}\text { Scale } \\
\text { reacing }\end{array}$ & $\begin{array}{c}\text { Correction } \\
\text { to be } \\
\text { added }\end{array}$ & $\begin{array}{c}\text { Scale } \\
\text { reading }\end{array}$ & $\begin{array}{c}\text { Correction } \\
\text { to be } \\
\text { added }\end{array}$ & $\begin{array}{c}\text { Scale } \\
\text { reading }\end{array}$ & $\begin{array}{c}\text { Correction } \\
\text { to be } \\
\text { added }\end{array}$ \\
\cline { 1 - 2 } 100 & 0 & 65 & 0.50 & 30 & 0.45 \\
95 & 0.10 & 60 & 0.525 & 25 & 0.41 \\
90 & 0.20 & 55 & 0.54 & 20 & 0.35 \\
85 & 0.28 & 50 & 0.55 & 15 & 0.28 \\
80 & 0.35 & 45 & 0.54 & 10 & 0.20 \\
75 & 0.41 & 40 & 0.53 & 5 & 0.10 \\
70 & 0.46 & 35 & 0.50 & 2 & 0.05 \\
\hline
\end{tabular}


4. THE SPECIFIC ROTATION OF DEXTROSE FOR WAVE LENGTH 5461 A AND ITS INTERPOLATION FORMULA

In columns 8 of Tables $4,5,6$, and 7 are given the absolute rotations of the solutions at each of the four concentrations less than normal for the wave length $546 \mathrm{r} \mathrm{A}$. The readings were as numerous and as carefully observed in each experiment as in the case of the normal solution. The accepted mean was converted into the rotation of the $\mathrm{n} / 5$ normal solution by the simple arithmetical proportion and application of the correction for the change of specific rotation when the concentration differed from the normality desired. These corrected values are recorded in columns 9 of Tables 4, 5, 6, and 7 .

The mean monochromatic rotations for the five concentrations are collected in Table 9 and the values converted into specific rotations by the formula

$$
[\alpha]_{5461 \mathrm{~L}}^{20.0} \frac{\alpha \times 100.00}{2 \times \text { weight dextrose in vacuo }}
$$

In calculating the atmospheric buoyancy correction the meanvalue of the density of anhydrous dextrose was taken to be I.54. This is the rounded-off mean of three values reported, ${ }^{23}$ namely, those of Pionchon (1.538), Bödecker (1.5384), and Schoorl (r.544). The density of the air in the balance case was computed from its temperature and the barometric pressure.

TABLE 9

Summary of Data on Monochromatic Rotations of Dextrose Solutions

\begin{tabular}{|c|c|c|c|c|}
\hline Normality of solution & $\begin{array}{l}\text { Vacuum } \\
\text { weight of } \\
\text { dextrose } \\
\text { in } 100 \mathrm{cc}\end{array}$ & $\begin{array}{c}\text { Rotation } \\
\text { observed } \\
\lambda=5461 \mathrm{~A}\end{array}$ & $\begin{array}{c}\text { Rotation } \\
\text { calculated } \\
\text { from } \\
\text { formula }\end{array}$ & $\begin{array}{c}{[\alpha]_{5461 \Lambda}^{20.0}} \\
\text { calculated } \\
\text { from } \\
\text { formula }\end{array}$ \\
\hline 1 & 2 & 3 & 4 & 5 \\
\hline N................. & $\begin{array}{c}\mathrm{g} \\
32.2515\end{array}$ & $\begin{array}{l}\text { deg. } \\
40.897\end{array}$ & $\begin{array}{l}\text { deg. } \\
40.898\end{array}$ & $\begin{array}{l}\text { deg. } \\
63.404\end{array}$ \\
\hline 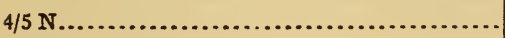 & 25.801 & $32.574_{5}$ & 32.576 & 63.129 \\
\hline 3/5 N.......................................... & 19.351 & 24. 328 & 24.326 & 62.855 \\
\hline 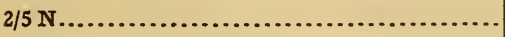 & 12.9005 & 16.142 & 16.147 & 62.581 \\
\hline 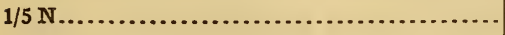 & 6.4503 & 8.042 & 8.038 & 62.306 \\
\hline
\end{tabular}

${ }^{23}$ v. Lippmann, Die Chemie der Zuckerarten, I, p. 265; 1904. 
As is apparent from column 5 of Table 9 the specific rotation undergoes a considerable dimunition as the concentration of dextrose decreases. A graphic plot showed that the relation was as closely linear as could be judged from the accuracy of the experiments. Mr. Phelps performed a least square adjustment of the straight line representing these values, weighting all points in proportion to the magnitude of the rotation. The result of this computation is the interpolation formula:

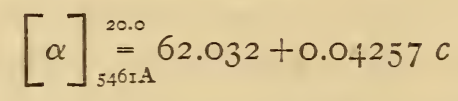

where $c$ is grams of dextrose weighed in vacuo and contained in Ioo cc of solution. This formula is valid for values of $c$ between $6 \mathrm{~g}$ and $32 \mathrm{~g}$.

From the interpolation formula the values of the rotation at each concentration were calculated and are recorded in column 4 of Table 9. The observed values are in column 3 .

It is frequently convenient to express concentration in per cent by weight in vacuo. Consequently, the specific rotation has been found by computation to be the following function of the per cent dextrose:

$$
[\alpha] \underset{5461 \mathrm{~A}}{=} 62.032+0.0422 p+0.0001897 p^{2}
$$

In concluding it is a pleasure to acknowledge the assistance rendered by Carl F. Snyder, who made duplicate observations of the rotations measured.

\section{SUMMARY}

I. Dextrose obtained from starch conversion products and from invert sugar has been purified by repeated crystallization from aqueous solution. A portion which was subjected to a fractional crystallization showed essential identity in all its fractions. Precipitation by ethyl alcohol produced a similar product.

2. The material after losing its water of crystallization at $60^{\circ} \mathrm{C}$ was freed from residual moisture by heating in a vacuum at $60^{\circ}$ to $80^{\circ} \mathrm{C}$ for several hours.

3. To prepare the solutions for polarization the dextrose was dried and the final weighing made after it was transferred to the volumetric flask. The substance was dissolved, made to volume at $20: 0 \mathrm{C}$, and the solution weighed.

4. The data were sufficient for the calculation of the density of dextrose solutions. The following formula, valid between 5 and 
30 per cent dextrose, gives densities reliable to 3 or 4 units in the fifth decimal place:

$$
\mathrm{D} \frac{20^{\circ}}{4^{\circ}}=0.99840+0.003788 p+0.000014 \mathrm{I} 2 p^{2}
$$

where $p$ is per cent dextrose by weight in vacuo.

5. The normal weight on the saccharimeter scale as determined by Bates and Jackson is $32.23 \mathrm{I} \mathrm{g}$ weighed in air with brass weights. This weight corresponds exactly with $26.000 \mathrm{~g}$ of sucrose and with conversion factors 34.620 for $\lambda=5892.5 \mathrm{~A}$ and 40.690 for $\lambda=$ $546 \mathrm{I}$ A. If the Herzfeld-Schönrock scale (conversion factor 34.657 ) is used, $32.264 \mathrm{~g}$ must be taken to rotate $100.00 \mathrm{~S}$.

6 . The rotations at concentrations less than normal are found to deviate considerably from proportionality. A table is given which indicates at $5^{\circ} \mathrm{S}$ intervals the corrections to be applied to the saccharimeter scale reading.

7. The rotation of the normal solution for $\lambda=546 \mathrm{I} \mathrm{A}$ is found to be $40: 897$. Since the normal quartz plate rotates $40: 690$, it is shown that the compensation in the quartz-wedge saccharimeter is imperfect and a slightly heterochromatic field results. This results in a lower degree of reproducibility than in the case of sucrose. This is overcome by an increased number of observations and some preliminary experience on the part of the observer.

8. The specific rotation for $\lambda=546 \mathrm{IA}$ is found to vary considerably with the concentration of dextrose. It may be represented by the formula,

$$
[\alpha]_{546 \mathrm{rA}}^{20.0} 62.032+0.04257 c
$$

when $c$ is grams of anhydrous dextrose weighed in vacuo and contained in roo cc of solution, or

$$
[\alpha]_{546 \mathrm{IA}}^{20.0} 62.032,0.04220 p+0.0001897 p^{2}
$$

where $p$ is per cent anhydrous dextrose by weight in vacuo.

WASHINGTON, July 7 , I9I6. 